\title{
NOOR BROCKMANN LUULETAMISEST
}

\author{
KRISTI VIIDING
}

$\mathrm{H}$

iljuti püstitas saksa kirjandusloolane Martin Klöker hüpoteesi, et esimeste ilmalike eestikeelsete värsside autor Reiner Brockmann või(nuk)s Martin Opitzi „Buch der Deutschen Poeterey” (1624) eeskujul koostada 1630. aastail esimese eesti poeetika, ning püüdis rekonstrueerida selle sisu Brockmanni Eesti-perioodist teadaolevate luuletuste, eelkõige programmilise „Teised tehku teisiti. Eestikeelse laulu lugejale” põhjal (Klöker, ilmumas 2016). ${ }^{1}$ Ent nii Brockmanni poetoloogilise programmi rekonstrueerimisel kui ka tema eesti keele vaimustuse tagamaade kontekstualiseerimisel ${ }^{2}$ on seni olnud personaalse allikmaterjali puudumise tõttu keeruline eristada, millised seisukohad kujunesid Brockmannil välja juba Saksamaal ja millised alles Tallinnas, sh milline oli saksa barokkpoeedi Paul Flemingi, aga ka esimese saksa poeetika autori Martin Opitzi mõju Brockmannile. Osnabrücki ülikooli varase uusaja uurimise instituudi töögrupi algatus kaardistada süstemaatiliselt IdaEuroopa arhiivide ja raamatukogude isikutrükised tõi mõningast täiendust Brockmanni Eesti-perioodi trükistele, kuid ei lisanud uut Brockmanni Tallinna-perioodi eelse aja kohta. 2015. aasta suvel Hannoveris Gottfried Wilhelm Leibnizi raamatukogus varauusaegse saksa õpetlasperekonna Meibomide korrespondentsi läbi töötades õnnestus mul leida kolm Brockmanni autograafi perioodist september 1629 - oktoober 1633 (Familie Meibom: 1 40-43p). Lisades neile neljandana 1630. aastal Ernst Stapeli tragikomöödia „Rahu ja sõja võitlus"3 (Stapelius 1630) ilmumise puhul kirjutatud ja trükki jõudnud õnnitlusluuletuse, on käesolevas artiklis võimalik esmakordselt heita veidi süstemaatilisem pilk Brockmanni luuletamispõhimõtetele ja varasele biograafiale enne Eestisse saabumist.

\section{Biograafilised täpsustused}

Äsjaste tekstileidude põhjal on esiteks võimalik täpsustada Brockmanni eluloolisi asjaolusid ja dateeringuid aastatel 1629-1633. 1629. aasta septembris kirjutas Brockmann õnnitlusluuletuse veel Hamburgis olles, 9. mail 1630 juba Rostocki ülikoolis õppides. Sellessamas 9. mai kirjas tänab ta adressaati äsjase teelesaatmisluuletuse eest, mistõttu Brockmanni elukohavahetus Hamburgist Rostocki pidi aset leidma 1630. aasta avakuudel ning Hamburgi gümnaasiumis õppimise ajaks on seega $1628-1630 .{ }^{4}$ 1633. aasta oktoobris ei viibinud

${ }^{1}$ Tänan Martin Klökerit võimaluse eest kasutada tema saksakeelset ettekandeteksti enne selle publitseerimist artiklina.

${ }^{2}$ Keskseteks käsitlusteks on Brockmann 2000; Klöker 2005: 300-314; Lepajõe 2009.

${ }^{3}$ Luuletust mainib Klöker (2005: 301, märkus 118), kuid tal ei õnnestunud leida ühtki selle eksemplari. Käesolevas artiklis on kasutatud Wolfenbüttelis Herzog Augusti raamatukogus leiduvat eksemplari.

${ }^{4}$ Formaalne immatrikuleerumine Rostocki ülikooli oli toimunud juba 1623. aasta talve- 
Brockmann aga enam Rostockis, vaid taas Hamburgis, nagu 17. oktoobril 1633 Helmstedti saadetud kiri tõendab.

Olulisim info rullub lahti seoses nende kolme käsikirjalise läkituse adressaadiga - mehega, keda senistest Reiner Brockmanni eluloo käsitlustest ei leia, kuid kes oli Brockmannile Tallinna-perioodi eel sõbraks ja eeskujuks: luterlik teoloog Brandanus Daetrius (Brandan Dätri). Brockmanni eakaaslasena 4. juunil 1607. aastal Hamburgis kirjutus- ja rehkendusõpetaja peres sündinud Daetrius oli kaotanud isa 1626. aastal nagu Brockmanngi. Eelkõige seovad neid ühised õpiaastad Hamburgi gümnaasiumis, ${ }^{5}$ kust Daetrius suundus 1630. aasta mais kuueks aastaks Helmstedti professor Georg Calixtuse juurde teoloogiat õppima. Seejärel sai temast kaheks aastaks Rootsi saadiku Hugo Grotiuse saatkonna pastor Pariisis. Järgnenud aastail täitis Daetrius pastoriametit Göttingeni lähedal Weendes, Hannoveris, Hildesheimis ja Aurichis. 1643. aastal doktoreerus Daetrius Helmstedti ülikoolis ning 1646. aastal sai temast Braunschweigi linna superintendent. 1662. aastast kuni surmani 1668. aastal oli Daetrius Braunschweigi linna superintendent, elu lõpuaastail ka abt ning konsistooriumi eesistuja Riddagshauseni kloostris Braunschweigis. Riddagshauseni kloostrikirikusse on ta ka maetud (Meyer 1957).

Aastail 1628-1633 oli Daetrius Brockmanni lähimaid sõpru. 17. oktoobril 1633, vähem kui aasta enne Brockmanni lahkumist Saksamaalt Eestisse, kirjeldas Brockmann oma sõprust Daetriusega tollele saadetud läkituse alguses (Familie Meibom: 143 , vt ill 1): ${ }^{6}$

\section{Tervist, sõprust ja kuulekust!}

Silmapaistvaim ja õpetatuim Brandanus, soosija, sõber ja ülimalt austatud vend! Ei sinu järjekindel vaikimine ega ka vahemaa, mis meid lahutab, suuda mind iial mõjutada, et seaksin su tunded kuidagigi kahtluse alla. Olen kaugel väitmast, et meie ühisest sõprusest on miskit kadunud, nii nagu ma ka ei kahtle, et sellele on sinu lahkumise järel lisandunud oluline edenemine, sest taotleme me ju Horatiuse ütlust mööda silme alt eemaldatud voorust. ${ }^{7} \mathrm{Ja}$ mu siinne järeldus ei ole asjatu: selle asja rikkalikuks tõenduseks on sinu lähedaste vahendusel mulle ikka ja jälle sinu sõnadega lausutud tervitused, mis on olnud mulle nii meeldivad kui üldse võimalik. Seetõttu ei tasu ma selle eest mitte üksnes sõnadega, vaid lisan ka need kirjaread. Oleksin seda kiiremini teinud, kui oleksin teadnud, kus paigus viibid, või kui teiste kaudu oleks enne su kirjade saatmist siia midagi

semestril (Matrikelportal Rostock - Datenbankedition der Immatrikulationen an der Universität Rostock seit 1419. http://matrikel.uni-rostock.de/index.action [10. VIII 2015]).

${ }^{5}$ Daetriuse nimi seisab Hamburgi gümnaasiumi matriklis vahetult Brockmanni järel number 335 all: Brockmann immatrikuleerus juulis, Daetrius detsembris 1628 (Sillem: 1891: 17).

${ }^{6}$ Ladinakeelsetes kirjades tarvitatud kreekakeelsed tekstiosad on jäetud käesolevas tõlkes kreeka keelde, sest enamjaolt on Brockmann need ise varustanud vahetult järgneva ladinakeelse tõlkega. Kreekakeelsete tekstiosade ortograafia, rõhu- ja hõngusmärgid on jäetud ühtlustamata ja normeerimata.

${ }^{7}$ Horatius, Carmen 3,24,31-32 (siin ja edaspidi tähistab antiiksetele luuleteostele viitamisel esimene number raamatut, teine luuletuse numbrit, kolmas värsiridade numbrit. Proosatekstide puhul viitab teine number peatükile, kolmas paragrahvile või lõigule, draamatekstide puhul on viidatud värsirea numbrile). 


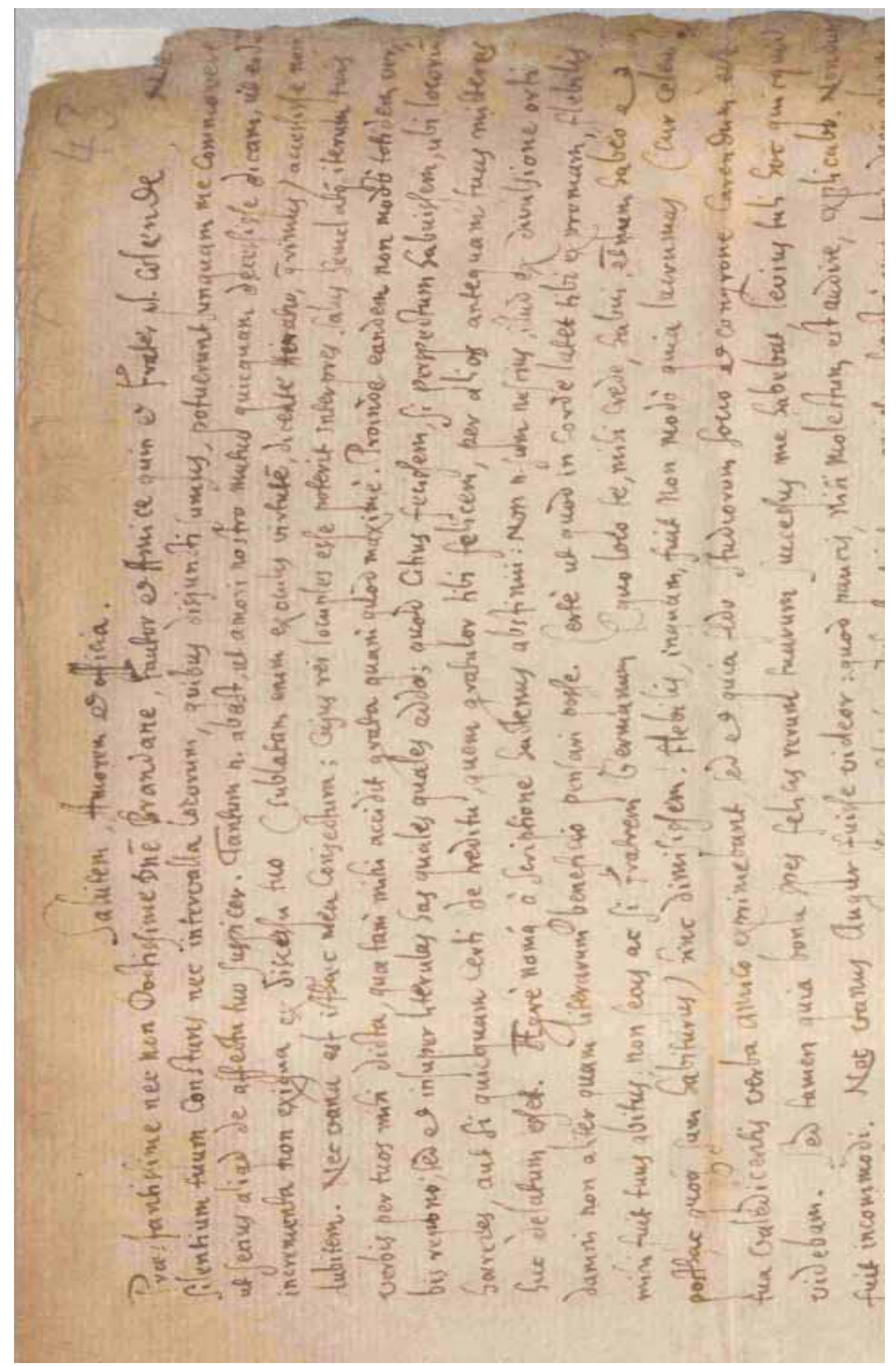

lllustratsio on 1. Fragment Reiner Brockmanni kirjast noorpõlvesõber Brandanus Daetriusele 17. oktoobrist 1633 (Familie Meibom: 1 43). 
kindlamat jõudnud su naasmise kohta, mille õnnestumise puhul sind õnnitlen. Olen ju siiani meelehärmiga kirjutamisest hoidunud, ehkki ma tean ju, et seda lahkuminekust sündinud kaotust ei saa korvata muudmoodi kui kirjadega heastades. Selleks et väljendada seda, mis südames tõepoolest varjul: sinu lahkumine oli mulle tõesti väga nutune, täpselt nii, nagu oleksin siit teele saatnud oma lihase venna (just sellises positsioonis, usu mind, olid sa minu jaoks ja oled praegugi ja jääd edaspidigi). Kinnitan, see oli nutune (miks peaksin varjama?), sest sinu sõnad lahkuvale sõbrale ei meelitanud välja üksnes pisaraid, vaid jätsid mu ilmset puudust tundma ustavast opingukaaslasest ja meriangerjast. ${ }^{8}$ Kuid kuna mind valdas hea lootus sinu asjade õnnelikule edenemisele, talusin seda mõningast ebameeldivust siiski kergemini.

Sõpruse kirjeldus jätkub selles Brockmanni seni teadaolevaist kõige autobiograafilisemas kirjas poeetilis-filoloogilise ekskursiga, millesarnast Brockmanni teistes säilinud kirjades leida pole. Ta mainib üht adressaadi lahkumishetkel aset leidnud esemekaotust, tõlgendades seda tulevikuendena. Ende selgitus lähtub varauusaja õpetatud teaduspublikatsioonide kombel sõnade derivatsioonist ja etümoloogiast. Ent sõna finge ('kujutle, kujuta ette') kasutamine juhib lugeja mõtte suunas, et Brockmanni esitatud tuletuskäike ja etümoloogiaid ei saa siin võtta tõsiteaduslikkust taotleva mõttearendusena, vaid õpetatud ja mängulise elegantsusena. Sama näitab võrdlus tolleaegsete kesksete sõnaraamatutega (Calepinus 1590; Soranus 1696 [1571]), mis ei kinnita ühtki Brockmanni esitatud etümoloogiaist. Mõttekäigu lõpuosas seob Brockmann noa ja noatupe allegooria varakambri ja varanduse võrdpildiga. Võrdlusosiste sarnasus Lutheri kuulsa mõttekäiguga „keeled on noatuped, millesse on torgatud vaimu noad. Keeled on varakamber, milles seda kallisvara kantakse" (Luther 1899: 38, 8-9) juhib Brockmanni idee allikat otsides Lutheri juurde. Ent mõttekäik tervikuna jääb Brockmannil kirjeldama siiski inimsaatuse ja tunnete valdkonda, Rostocki kui õnnetu saatusega hädakoobast ning Helmstedti kui vaimu arengule soodsat keskkonda. Lutheri pedagoogilis-lingvistilise põhimõtteni Brockmann oma mõttekäiku ei arenda (vt lähemalt Lepajõe 2009: 766, 2013: 86).

Ja ma ei ole ilmsesti tühjakuulutaja: selgitan seda nü̈̈d lühidalt, kui ei ole raske seda kuulata. Kahtlemata ei ole sa veel unustanud, et sa oma lahkumishetkel otsisid asjatult oma noatuppe, nii et pidid kaotatu asemele võtma teise, venna ulatatud noatupe. Selle kaotatud noatupe (lad vagina), mis oli minu omaga väga sarnane, võtsin ma enda oma pähe mõtlematult ära, ja leidsin selle kohe pärast seda, kui ma sinu juurest koju jõudsin. Kujutle nü̈̈d, et sõna „vagina”" tuleks sõnast „hädakisa” (lad vagitus) ja tähistaks

${ }^{8}$ Meriangerjas (lad conger) - antiikse ettekujutuse järgi võisid meriangerjas ja mureen üksteisel vajadusel saba ära hammustada, kuid jäid mõlemad ellu (Aristoteles, Füüsika 9,2; Plinius, Looduslugu 9,185).

${ }^{9}$ Brockmann mängib sõna vagina mitme tähendusega: a) nooletupp, b) viljatera kest, nii nagu see tollastes sõnaraamatutes käibis (nt Faber Soranus 1696: 2416). Ta jätab kasutamata Plautuse komöödiast „Pseudolus” pärineva naiste suguorgani obstsöönse tähenduse, millest kujunes alles hiljem, 1680-ndatel lõpuks meditsiinitermin. Sõna vagina kasutas ühel korral sõna vagitus ('lapse hädakisa, nutt') tähenduses hilisantiikne mütograaf Fulgentius (Expositio Virgilianae continentiae secundum philosophos moralis p 151M) ja sellel põhineb ka Brockmanni pseudoetümoloogiline sõnamäng. 
sellest tulenevalt „vaenulikku saatust” (fortuna), ja et sellest sõnast omakorda tuletuks ka sõna „urg” (fovea) või „uuristatud koobas”. Ent nuga pane tähistama seda vahedat vaimu, millega tuli katki lõigata sünged lõngad, mida Saatus oli lõiminud. Kui sa seda nõnda seostatuna vaatad, siis näed, et sinult langeb ja jääb sellega selja taha kogu kurbusekoorem ning selle asemel leiab edenemist rõõmukülv, millest hiljem hakkad mõotma rikkalikku saaki. Ja seda sa ju vastavalt lubadusele teedki, kui kasutad helde, väljapaistvaima hertsogi ${ }^{10}$ stipendiumit, Calixtuse ja Praetoriuse ${ }^{11}$ juhti-

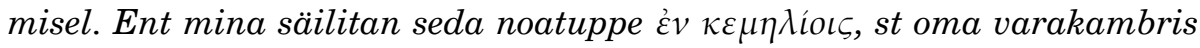
ja oma noa ümber ning selle iga vaatamiskord (heidan sellele pilgu iga kord, kui on vaja sü̈̈a) meenutab mulle Sind. Tee sinagi samuti ja meenuta mind, iga kord kui pead oma noa paljastama.

Järgmiseks avaldab Brockmann oma tulevikusoovi minna edasi õppima Helmstedti ülikooli teoloogiaprofessori Georg Calixtuse (professuur 16141656) juurde. Endiselt õpingukaaslaselt loodab ta selleks toetust:

Oh, kui see enne ei petaks mind, kui meie kokkusaamine oleks sama lihtne, kui on noa ja tupe ühendamine! Kuid et see oleks lihtne, on suur osa jäänud sinu kätte, parim Brandanus, kes - juhul kui mul tekib juhus liikuda teie juurde, võiksid sõnakesega märku anda oma juhendajatele (loodan, et nad on meil Sinuga ühised). Sest Sinule on ju $\mu \varepsilon \gamma \alpha \dot{\alpha} \eta \eta \tilde{v} v \dot{\alpha} v \varepsilon \omega \dot{\alpha} \theta \eta \theta \dot{v} \rho \alpha$, st suur uks avatud, mille kaudu saad takistamatul sammul siseneda sellesse kõrguvasse tarkuse ja kuulsuse templisse. Oh kui see oleks mullegi lubatud, kui ma kohe oleksin olnud isanda jälgedes käija! Kuid kardan-kardan, et mind, kellele saatus on siiani olnud pigem võõrasema kui ema eest ${ }^{12}$, ei hoita sellest teest mitte ainult eemal, vaid süüdistatakse isegi kitsukese jalgraja

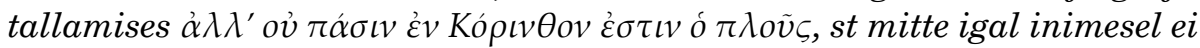
ole lubatud jõuda Korinthosesse ${ }^{13}$. Vahepeal on olnud mulle lohutuseks see, et sulle osaks saanud hüve vili pole tulevikus mulle kui sõbralegi võõras. Loodan, et see lootus ei peta sind ega purune. Ülesanne, mille mulle andsid, et annaksin reisialbumi mõningatele sõpradele, viisin täide, kästes sind tervitada iga üksiku nimel. Neist ainukesena läks Maxius Leipzigisse. ${ }^{14}$

Kirja järgmises osas käsitleb Brockmann tollase juhuluuletamise praktikaga kaasnevaid detaile - luuletuste kadumist adressaadini jõudmata, luuletuste koopiate säilitamist autori kogus ja luuletuste kollektsioneerimist:

\footnotetext{
${ }^{10}$ Braunschweig-Lüneburgi hertsogiks oli perioodil 1610-1636 August I.

${ }^{11}$ Helmstedti ülikoolis ei töötanud 1633. aastal ühtki Praetoriuse (delatiniseeritult Richteri ega Schultzi) nimelist professorit ega õppejõudu. Brockmann viitab oletatavasti mõnele varasemale Praetoriusele (Ahrens 2004).

${ }^{12}$ Looduse kui võõrasema või ema kohta vt Plinius, Looduslugu 7,2; Quintilianus, Kõnekunsti alused 12,1,2 jt, varauusaegsetel embleemidel ja vanasõnaraamatutes aga saatus kui võõrasema või ema, nt Erasmus, Adagia 1,8,64 jm.

${ }^{13}$ Horatius, Epistlid 1,17,36; Erasmus, Adagia 1,4,1.

${ }^{14}$ Maxiuse-nimelist ei ole Hamburgi gümnaasiumi matriklisse immatrikuleeritud (Sillem 1891).
} 
Palun sind, mu Brandanus, et sa lubaksid tõrkumata hüvitada selle luuletuse kadumise, mille kirjutasid minu sünnipäevaks, mida ma mitte just ammu tähistasin. Hüvitada saad nii, kui saadad selle uuesti kirjapanduna mulle. Sina võid ainsana selle vilja, mille sa oma andekuse teiste tõenduste seas justkui ise sigitasid, alal hoida ja mulle uuesti saata. Kui saadad, saad minult vastu topelttänu: ühe loomise, teise alalhoidmise eest. Selle taasnõudmise põhjuseks on soov koondada sinu muud kirjutised nagu ka

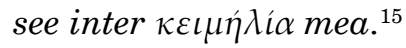

Kirja lõpus avaldab Brockmann, et ta on Hamburgis pedagoogiametis, mis toob küll vähe sisse, kuid millest veelgi enam häirib teda ajapuudus akadeemilisteks tegevusteks. Samuti kinnitab ta veel kord soovi siirduda õppima Helmstedti:

Kui sa kirjutaksid mulle sellestki, mida praegu tegelikult teed ja milliseid õpinguid läbid, teeksid mind väga tänulikuks. Mina kulutan kogu pedagoogitööst ülejääva aja (mida on tõesti ülinapilt) varem akadeemias kuuldu praktiseerimisele ja kordamisele. Elan ju nü̈̈dki talutavates tingimustes, kuid kogen siiski paljusid, sinugi kogemuse põhjal tihti viidatud majandusmuresid. Kus ma järgmisel aastal tegutsen, ei ole veel selge. Ma ei ihka ega soovi miskit meelsamini, kui et mul oleks võimalik sinu seltsis oma elu mööda saata ja üheskoos óppida. Kuid see tuleb usaldada Jumalale ja ajale. Uudistest, mida peaksin lisama, ei tule meelde muud, kui et uueks sündikuks valiti isand Meuser ja et ta nõnda jättis tagaplaanile Broderus Pauli. Nende sõnadega jää hüvasti ja ole oma sõpruses minu vastu jätkuvalt heasoovlik. Kirjutasin Hamburgis 17. oktoobril 1633.

Sinu innukaim Reinerus Brocmann ${ }^{16}$ Schwaanist Mecklenburgist.

Seega ei alustanud Brockmann oma pedagoogikarjääri mitte Tallinnas, nagu kujutatud senistes Brockmanni elulookirjeldustes (nt Telschow 2000: 34 ), vaid juba varem, hiljemalt 1633. aasta sügisel Hamburgis. Ehkki käesolevast kirjast ei selgu, mis aine(te) õpetajana ja millises vormis (avalikus või erakoolis või hoopis eraõpetajana) Brockmann Hamburgis 1633. aastal tegutses, oli tema õpetajatöö kogemus 1633/1634. õppeaastal ilmsesti väga intensiivne ning võib-olla üks põhjuseid, miks Tallinna gümnaasiumi rektor Heinrich Vulpius teda Tallinna gümnaasiumile soovitada söandas. Samuti selgub, et Brockmanni enese visandatud pildi järgi ei olnud tema Tallinnasse siirdumise tähtsaimaks ajendiks sugugi Kolmekümneaastane sõda, vaid majanduslik kitsikus ja akadeemilisuse puudus, millele Brockmann lootis ilmselt Tallinnas professorikohal leevendust leida. Ent käesolev kiri ei lase Brockmanni Tallinnasse tulekut tema enda huvide valguses paista mitte kauaoodatud missioonina, vaid viletsama alternatiivina edasiõppimisele Helmstedti reformülikoolis tuntud teoloogi Calixtuse juures.

${ }^{15}$ Oma varakambritesse (lad, $\mathrm{kr}$ ).

${ }^{16}$ Ladinakeelsete tekstide all on alati Reinerus Brocmann(us). 


\section{Brockmanni varased tekstid kirjanduslike huvide peegeldajana}

Ajastutüüpiliste kirjanduspraktikate üle ei mõtiskle Brockmann aga üksnes selles 1633. aastast pärit kirjas. Eranditult kõik kolm Brockmanni varase perioodi ladinakeelset juhuluuletust, õnnitlus värsskõne pidamise (1629), raamatu ilmumise (1630) ning teelemineku puhul (1630), käsitlevad mõnd värsistamise või luule mõjuga seotud aspekti. 3. septembril 1629 Hamburgist Brandanus Daetriusele saadetud kuuevärsilises, anagrammi põhjal kirjutatud epigrammis loob Brockmann kujutluspildi muusade juhist Apollonist, kes muusade salga ees kiidab Hamburgi gümnaasiumis tunnete talitsemise teemal kõne pidanud Brandanus Daetriust (Familie Meibom: 1 40). Apolloni kiidusõnad annavad esmalt 3.-4. värsis hinnangu kõne sisule, varieerides ladina keele õpetusest hästi tuntud sententsi „habe ei tee veel filosoofiks” (barba non philosophum facit). ${ }^{17}$ Viiendas ja kuuendas värsis lisab Apollon kiiduargumendi kõne värsistatuse eest: just värsivormi kasutamine gümnaasiumi- ja ülikoolikõnedes tavapärase proosavormi asemel tõstvat adressaadi kõrgemale barbaarsusest. Luuletus ei lõpe juhuluulele tavapärase motiiviga ,ja ma õnnitlen sind sel puhul südamest”, vaid just ülistus värsivormi kasutamise puhul moodustab luuletuse puändi. Kiiduväärt pole Brockmanni suu läbi kõneleva Apolloni meelest seejuures mitte pelgalt värsivormi kasutamine kui tehniline oskus, vaid kõne sisu ja värsimõõdu meisterlik kooskõla. Teisiti sõnastades: Brockmanni arvates on kohane kõneleda tunnetest just värsivormis, värsimõõtu seatuna (vt ill 2):
Oma
Brandanus Doetriusele
Hamburgi gümnaasiumis
avalikult peetud kõne
„Tunnete talitsemisest”
puhul südamest onnnitledes
Brandanus Doetrius
anagrammina
Ei ole saabunud rumal
Selgitus:

(1) Kui saatus tõi teate su astumise kohta kõnepulti, laulis soosiv Apollon oma muusadele nii: (3) „Siia ei saabunud rumal, ehkki ta ei ole ka habemega - kunagi ei ole habe muutnud harimatuid filosoofiks. (5) Minu hinnangul ei ole saabuja ei rumal ega barbaarne, kas kuuled? Kõik tema sõnad sobivad värsimõõduga."

Reinerus Brocmann, Schwaanist Mecklenburgist,

3. septembril 1629.

\footnotetext{
${ }^{17}$ Antiikkirjanduses, keskajal ja renessansiautoreil paljudes variantides käibinud mõttetera, nt Aulus Gellius, Atika ööd 9,2,4; vrd ka Erasmus, Adagia 1,2,95: Barbae tenus sapientes („Kuni habemeni filosoofid”).
} 


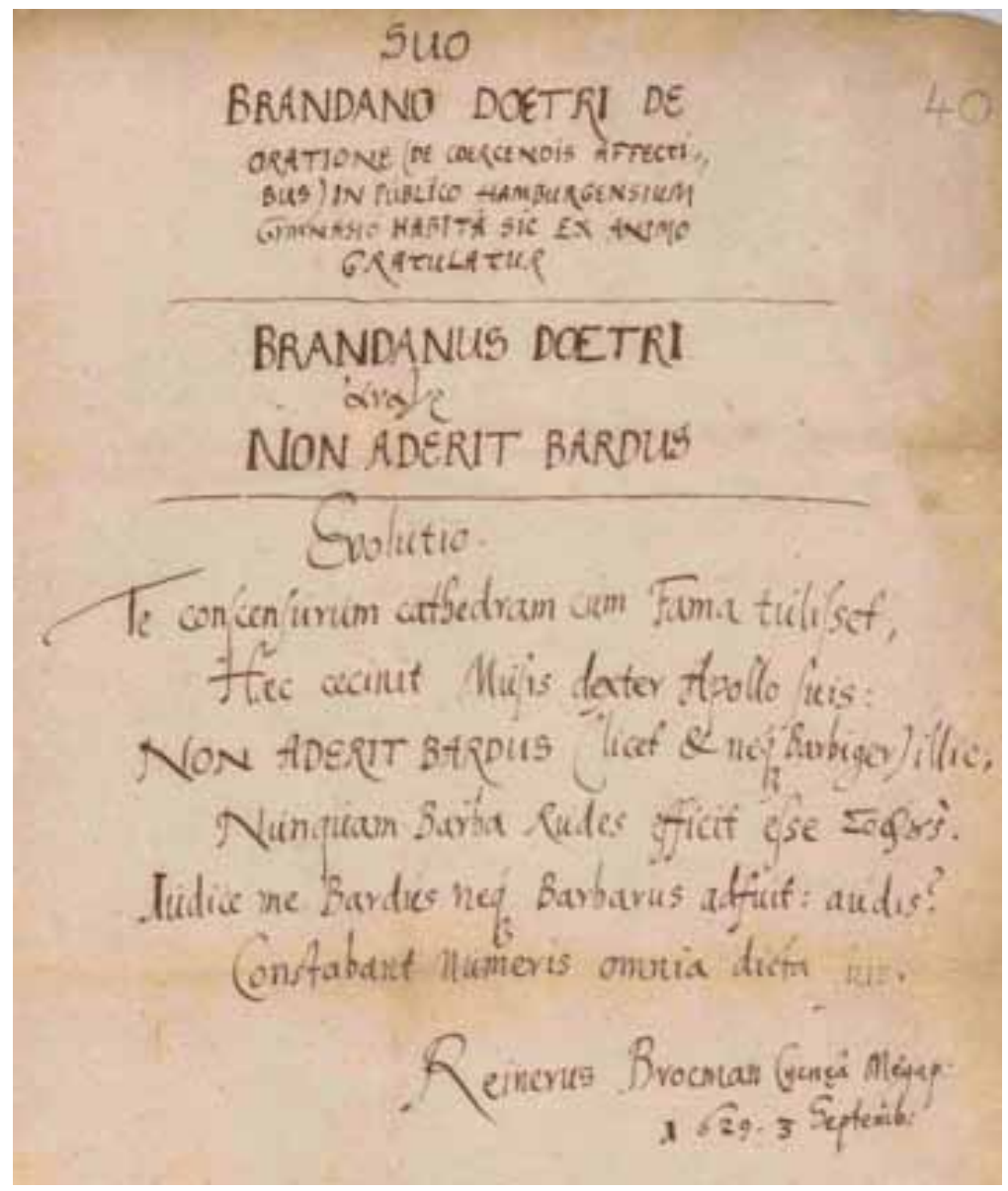

lllustratsioon 2. 3. septembril 1629 Brandanus Daetriusele saadetud epigramm (Familie Meibom: 1 40).

Teinegi juhuluuletus on eleegilistes distihhonides epigramm, mille aluseks on anagramm adressaadi Ernst ${ }^{18}$ nimest. Luuletus trükiti Ernst Stapeli nime all ilmunud saksakeelse tragikomöödia „Irenaromachia ehk Rahu ja sõja võitlus” juures dedikatsioonina paljude teiste autorite pühendusluuletuste hulgas. ${ }^{19}$ Brockmanni onnitlusluuletus ei keskendu ka siin mitte draamateose sisu, eeskujude ega stiili käsitlemisele, ${ }^{20}$ vaid vormilisele - näitemängu üles-

${ }^{18}$ Ernst Stapel (?-1635), Vestfaalist Lemgost pärit poeet; saksa luuletaja Johann Rist kasutas tema nime oma esimese draama „Irenaromachia” avaldamisel ning abiellus hiljem Stapeli õega. Stapeli enda luulest pole midagi säilinud (Holstein 1893: 448).

${ }^{19}$ Üksnes tragikomöödia epiloog, pöördumine Momuse poole on ladinakeelne (Hvii pöördel).

20 „Irenaromachia” jäljendab pealkirjas küll hellenistlikku Homerose-paroodiat „Batrachomyomachia” („Konnade ja hiirte sõda”), kuid draama põhisisu moodustab jumalate nõukogu rahu ja sõja küsimuse üle ning talupoegadest sõdurite (ositi alamsaksakeelne) vestlus marsi ajal. „Batrachomyomachia” oli varauusaegses kirjanduses ja kooliõpetuses väga populaarne, seda peeti ekslikult Homerose teoseks (vt Glei 1997: vrg 496; retseptsiooni kohta Kaju, Viiding 2014: 66-67). Jaan Bergmanni tõlget eesti keelde vt http://www.fl.ut.ee/et/522038. 
ehitusele. Brockmanni väitel oskab adressaat näitemängu sel kombel osadeks jagada, et teose terviklikkus säilib. Ta ei diskuteeri täpse vaatuste arvu ega funktsioonide üle ${ }^{21}$ - vaatusi on „Irenaromachias” kolm, kuid kaks esimest jagunevad taevases sfääris toimuvaks jumalate nõukoguks ning sellele järgnevaks talupoegade marsiks, nii et stseene on kokku viis -, vaid rõhutab jaotuse sobivust ja teose terviklikkust (decente more, v 4):

\section{Ernestus Stapelius \\ anagrammina \\ Valdad näitemängu osi \\ Selgitus:}

(1) Osadest moodustub tervik - see, kes seda teab, selle valduses on suur oskus. (3) Sina, Stapelius, valdad näitemängu osi, jagades oma näitemängu meeldival kombel osadeks. (5) Sa õpetad tõesti kaunilt, osates kaunilt jagada, mistõttu kõik armastavad sind jäägitult. (7) Jätka! Sellest ei sünni sulle mitte pelgalt au, vaid põllumehe kombel hakkad sa lõikama vaeva väärikat tasu.

Oma käega

Reinerus Brocmannus Schwaanist Mecklenburgist.

Värsistamis- ning struktureerimisoskuse väärtustamise kõrval on noor Brockmann oma kolmandas ja ühtlasi pikimas juhuluuletuses ning sellele lisatud proosakommentaaris (sellise refleksiooni lisamine oma värsside loomispõhimõtete kohta on Eesti- ja Liivimaa juhuluule taustal väga haruldane) käsitlenud luule ülesannet, mõju ja mõõtu (Familie Meibom: 41-41p). ${ }^{22} 42$ värsi pikkuses eleegilistes distihhonides kirjutatud teelesaatmisluuletuses, mille adressaadiks on jälle Brandanus Daetrius, iseloomustab Brockmann värssides 19-20 luulet kui rõõmutoojat, lisades sellega oma eelmises luuletuses rõhutatud luule õpetuslikule rollile luule emotsionaalse, Horatiuse „Luulekunstist” tuntud delectare-funktsiooni. Just rõõmu tekitamisvõimes peitub luule vägi (vis, v 23-24), ent mujalt saadetud luule jääb Brockmanni kirjelduses siiski koosolemise ja vahetu suhtlemise aseaineks (ill 3).

\section{Brandanus Daetrius Hamburgist anagrammina \\ Lahkudes oled võimas: rumalad kõhelgu}

(1) Ma arvan, et teie gümnaasiumist lahkumine, oo Brandanus, ei jäta midagi muud alles peale murede. ${ }^{23}$ Sest mind juhib imetlusväärselt meie sõpruse magusus ja ustavus ei luba sind unustada.

${ }^{21}$ Horatiuse kanoonilise „Luulekunsti” v 189-190 viievaatuselise näitemänguideaali mõjul jagati Rooma komöödiad vaatustesse alles renessansiajal. Varastes Rooma komöödia käsikirjades leidub kuni XV sajandini üksnes stseenide jada ilma vaatusepiirideta, XVI sajandi algusest alates on antiikkomöödiate väljaandmisel tavaks kujunenud vaatustesse jagamine. Seetõttu on mõneski tänapäevases komöödiate tekstiväljaandes vaatuste numbrid sulgudesse pandud.

${ }^{22}$ Ümbrikule on kirjutatud: Rostockis, 9. mail 1630. Lahkumiseleegia Brandanus Daetriusele Hamburgist lahkumise puhul. Oma Brandanus Daetriusele Rostockist Hamburgi.

${ }^{23}$ Kahe avavärsi tekst on märkimisväärse inversiooniga; tõlge lähtub sõnajärjest reor nil reliqui habere praeter curas. 


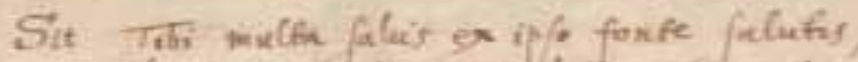
A que monfuli ques dafe offine dafuir

BRAN DANUIS DAET TRY FAMBLERENST. क्रaीe:

MAGNULS ERTS AEIENS: BAKDI THRDENT.

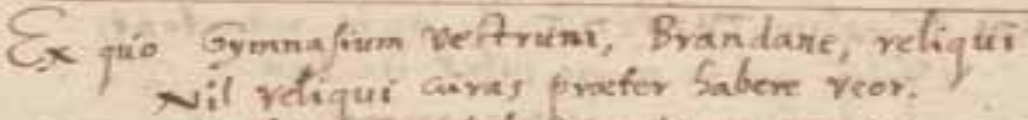

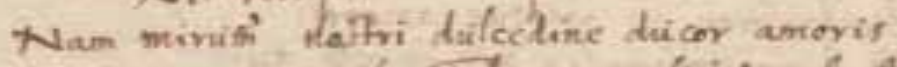

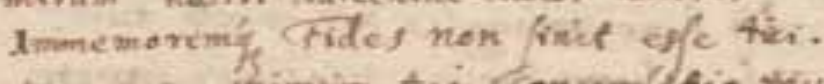

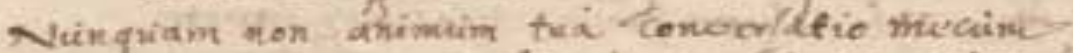
Teunquam mon pectics dexterd foriptia fubit.

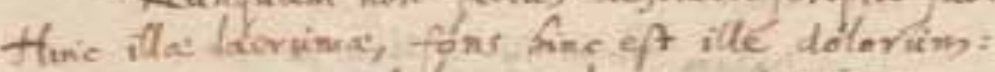
inge mean doleo corde, tirang vicam. fui mili diledi. voces st verba Sathlis Nom aid lire datier, nic manse's, os ve dafici. Nec mikises esfe pofes cierarum forfifin expors,

Tinuef oars cordis dimidia fa mer.

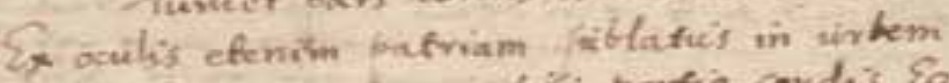

Sim non parua tili porfio cordis Ego. Distiba doda quibuis dacte mibi fruifa vousbits Teflantur meatem faty fiborgh triam.

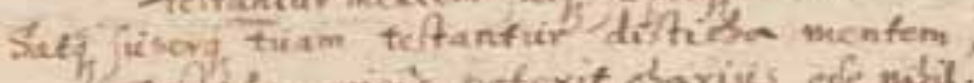
V) Dufich, queis poterit ebaries ofe nobil. Ha taia me. quoties lepo listida ressere latuia tffif Glent mirrs abilarare modis. Weribuis'si himmon lavitem, prafes mereris,

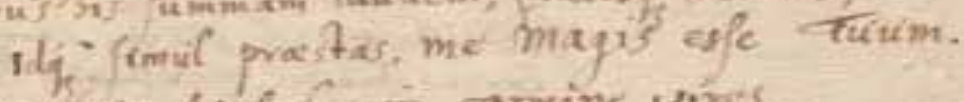

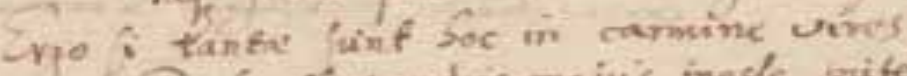
Praifunti pontics majus inesfe pites.

CPratens ficira pofes dave, quami quis carmine porfef: Nonrobil asperfus, nonnibit on movede. tambrivil cum nan alar anflines, ef tii Certis abi patriats sames mivice profenfis: Huic asers of nothre pars fimut of to schole.

lllustratsioon 3. 9. mail 1630 Rostockis kirjutatud teelesaatmisluuletus (Familie Meibom: 141 ). 
(5) Iial ei lähe ju meelest sinu vestlus minuga, iial ei kao südamest soosivad kirjutised. Sellest siis need pisarad ${ }^{24}$ siit on siis pärit see valudeallikas, miks süda valutab minu ja sinu pärast.

(9) Ei saa ma enam kuulda nii armsa kaaslase häält ega sõnu, ei anna ta enam kätt ega suud. Niisama vähe saad jagada mu ootamatuid muresidmu lõhestatud südame pool paisub. ${ }^{25}$

(13) Sinu silme alt kodulinna suundununa pole ma just tähtsusetu osa sinu südamest. Opetatud distihhonid, millega tõotasid mulle õpetatult edu, tõendavad sinu meelsust vägagi.

(17) Piisavalt tõendavad sinu meelt su värsid - värsid, millest kallim pole miski. Need sinu värsid muudavad mu rõõmsaks iga kord, kui neid loen, ja lõbustavad mind imepärasel moel. Nende värsside eest teenid sa ära ülima kiituse ja tänu, näidates ühtlasi seda, et ma olen veelgi enam sinu oma.

(23) Kui selles luuletuses ongi selline vägi, pea siiski meeles, et kohalolija kaalukus on veelgi suurem. Koos olles saad rohkemat anda, kui ükski luuletus seda suudab - üht-teist meenutab pilk, üht-teist meenutavad palged. (27) Sest et kui ma enam ei saa toitu Gambriviuselt ${ }^{26}$ ja sinagi lahkud siit minu ja teiste järel mujale, siis mine kindlana ning külasta kodumaad ja kodu, ent viibi siiski siin, jäädes ühtlasi meie kooli osaks.

(31) Kuid ma ei tee miskit: sinu jaoks on ju parem paik valmis, sinu muusadele pole kohane praegune paik. Ja isegi kui nood seavad end siia sisse, lahkud sina ise siiski vabatahtlikult isamaa paikadest.

(35) Siit lahkudes nimetatakse sind tõepoolest Suureks ja mitte asjatult: saad sa ju tõepoolest suureks. Viivitagu rumalad lahkumisega - sind ärgu miski viivitama pangu: mine õnnelikult sinna, kuhu su süda sul käsib minna.

(39) Vahepeal ära unusta aga meie sõprust, vaid soosi seda ikka oma vastustega. Nende sõnadega jää hüvasti, olles mul käskinud tervitada ja soosida igaüht meie omadest. Ja vasta neile [ridadele] mõni rida. Jää hüvasti.

Kirjutasin Rostockis 9. mail 1630 kõigis tõotustes sinu Reinerus Brocmann Schwaanist Mecklenburgist. ${ }^{27}$

Luuletusele lisatud proosakommentaaris tematiseerib Brockmann esmalt humanismi, sh humanistliku luule ühe keskse, mõõdu(kuse) probleemi. See on Brockmanni enesevõrdlus ajastu keskse programmiga, kokkuvõttev kinnitus Marju Lepajõe 2009. aastal avaldatud Brockmanni artiklis sõnastatule: „[m]õõt juurdub mõtlemises, seesmises inimeses, teostub otsustusvõimes ja väljendub keeles, suutlikkuses talitseda nii oma hinge kui keha. Ilus inimene on talitsetud inimene" (pikemalt Lepajõe 2009: 762-763). Brockmann naaseb siin ühtlasi oma varaseima, 1629. aasta luuletuse juurde tunnete ja (värsi) mõõdu seostest (ill 4):

${ }^{24}$ Antiikkirjanduses korduvalt kasutatud tsitaat, nt Terentius, Androslanna 126; Horatius, Epistlid 1,19,41.

${ }^{25}$ Sõber kui pool hingest esineb korduvalt Horatiuse „Oodides” - 1,3,8 (Vergiliuse kohta), 2,17,5 (Maecenase kohta).

${ }^{26}$ Müütiline germaanlaste kuningas, Marsuse poeg, legendi järgi Hamburgi linna rajaja.

${ }^{27}$ Post scriptum ladina keeles: Mu vend, ehkki [sulle] tundmatu, palub tervitada. Palun, et annaksid neile [kirjadele] lisatud [kirjad] edasi Esaiasele. Kui vastu kirjutad (mida ma palun), pane oma kirja peale: [jätkub saksa keeles] Rostockis, Küsida Matthias Sture juurest, kes elab Pikal tänaval „Poolkuus”. 


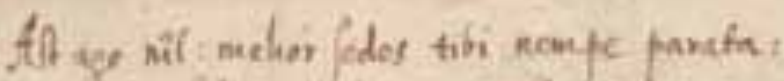

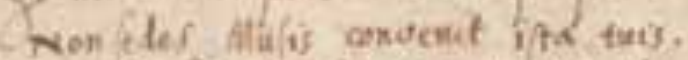

At t uf uf Sor sebeont dese; tumen ife velinguies

Patria quar minaimi neake libenke ldes.

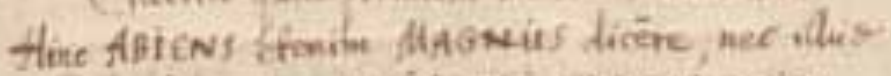

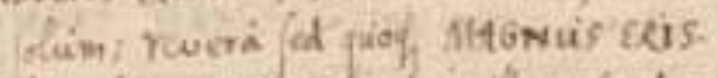

Bardi dicesfion TARDEN t, te ruila refurlent:

rfelis, quid te mens ialef irc tus.

Sherea botri nem is shlitis, anavi:

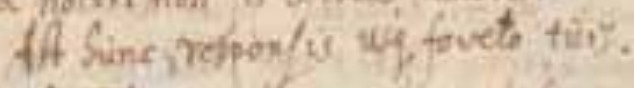

Afice vale falues jubens nuesaing fwere

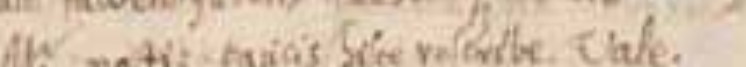

chatam Rofodis gllay a 50 .

Thist a fuo noin

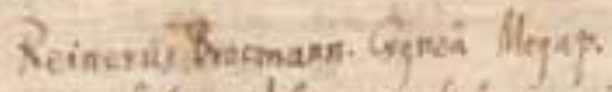

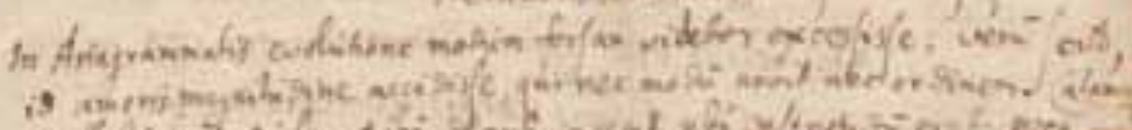

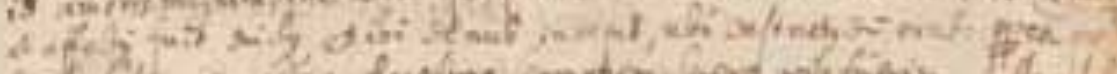

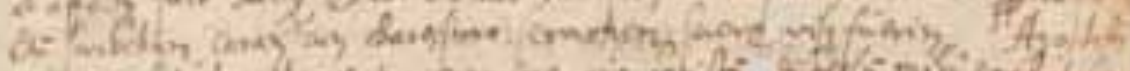

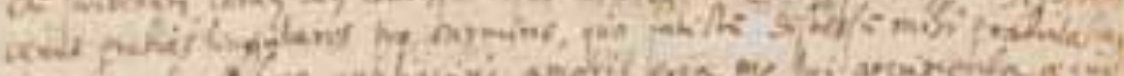

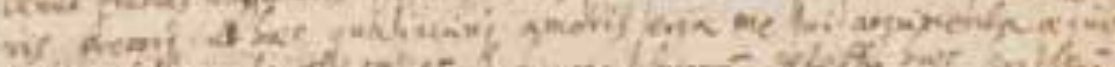

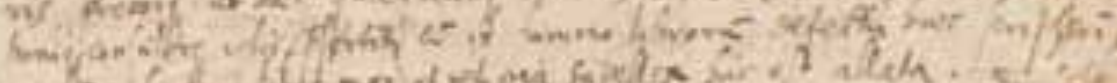

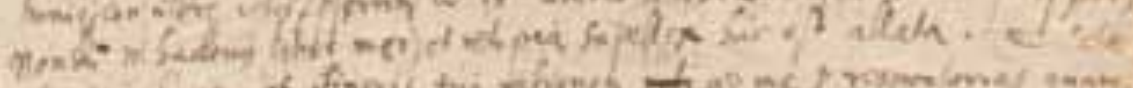

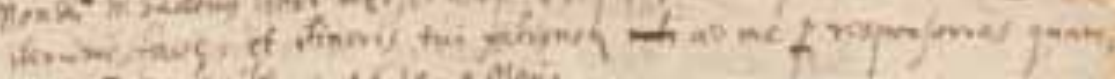

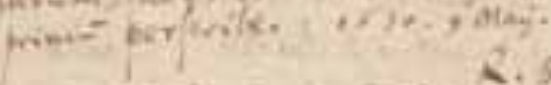

2. 5. $\cos x$

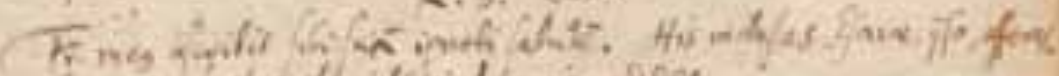

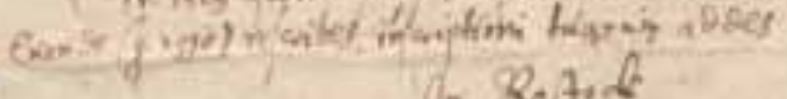

$$
\text { I. Reti, }
$$

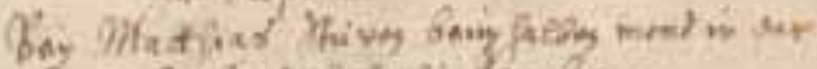

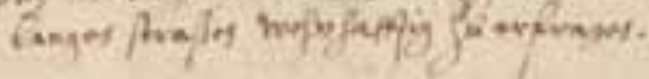

lllustratsio on 4. 9. mail 1630 kirjutatud luuletuse lõpp koos proosakommentaariga (Familie Meibom: 1 41p). 
Võib ehk tunduda, et anagrammi seletuses olen ületanud mõõdu. Ent tea, et see juhtus suure sõpruse pärast, mis ei tunne ei mõotu ega reegleid. Sulge juhtis tunne, alustades uuesti sealt, kus oleks tulnud lõpetada. Seetõttu panin kirja selle, mida armsaima [sõbra] juuresolekul oleksin sõnadesse seadnud.

Kommentaari lõpuosast selgub noore Brockmanni luuletamise oluline abivahend - raamatud. Ilmsesti on viide raamatuile kui koolihumanismis tüüpilisele luuletamise abivahendile: teema juurde sobivate motiivide ning õpetatud tsitaatide leidmise allikale. Luule ei sünni jumalikust inspiratsioonist, vaid kätkeb lisaks värsistamis- ja struktureerimisoskusele ka sobivate kirjanduslike inspiratsiooniallikate leidmise pädevust. Raamatuteta, s.o varasemate tekstideta sündinud luule pärast peab Brockmann vajalikuks vabandada:

Olen sulle veel kord erakordselt tänulik luuletuse eest, milles õnnitlesid mind eduka lahkumise puhul, ja palun, et tahaksid õiglaselt ja heatahtlikult vastu võtta need mõningased tõendused minu sõprusest sinu vastu, eriti kuna kirjutasin need raamatute täielikul puudumisel, sest siiani ei ole mu raamatud ega ülejäänud majakraam veel siia kohale jõudnud. Jää hüvasti ja ole ikka soosingus, ning kirjuta mulle, niipea kui saad, oma reisi kulgemise kohta vastus. 9. mail 1630.

Reinerus Brocmannus Schwaanist Mecklenburgist

\section{Kokkuvõtteks}

Võrreldes äsja leitud luuletusi ja kirja Brockmanni õpinguaastaist (16291633) tema hilisemate, Tallinna-perioodi omadega nähtub, et Brockmann elas kahekümnendate eluaastate alguses läbi intensiivse luuleteoreetiliste küsimuste ja luuletamispraktika üle mõtisklemise perioodi. Ajastutüüpilistest luuletamistavadest kiitis ta heaks tehniliste oskuste valdamise värsistamise, struktureerimise ja teemade-motiivide leidmise osas. Mõningast ebakõla tajus ta luule väe ning tunnete avaldamiseks sobiva mõõdu seostamisel humanistlike luuletamistavadega, st nende teemade puhul, mida humanistlikes poeetikates ei käsitletud. Poetoloogiahuvi oli esialgu siiski pelgalt teoreetiline, sest Brockmanni enda tolleaegsed luuletused on lihtsad eleegilistes distihhonides anagrammluuletused ega sisalda mingeid vormi-, keele- ega meetrumieksperimente. Rahvakeeled luuletamismeediumina polnud veel tema teadvusse jõudnud, ka mitte juhul, kui õnnitlusluuletuseks andis aluse rahvakeelne teos, nagu 1630. aastal avaldatud onnitlusluuletus näitab. Opitzit ega ühtki teist rahvakeelse luuletamise eestkõnelejat Brockmann veel ei maini.

Kui tahame seega luuletaja Reiner Brockmanni näha lisaks veendunud humanistile ka muutusteaja õpetlasena, siis saabus muutusteaeg tema luulesse alles pärast 1633. aastat, st 1634.-1635. aastal ja ilmsesti Tallinna gümnaasiumis töötades. Miks mitmekeelse (sh eestikeelse) ja paljuvormilise luuleharrastusega läks Tallinnas edukalt kaasa just Brockmann, aga mitte teised Tallinna gümnaasiumi tollased õppejõud, on aga seletatav just Brockmanni Tallinna-eelsete aastate aktiivse luuletamise üle reflekteerimise perioodiga. 
Eeskätt tänu sellele ettevalmistusele sai Brockmannilt Tallinnas „langeda koorem ning selle asemel leida edenemist rõõmukülv, millest sai mõõta rikkalikku [luule]saaki”.

Artikkel valmis Alamsaksi liidumaa toetatud uurimistöö käigus Wolfenbüttelis Hertsog Augusti raamatukogus. Tänan dr Elisabeth Hardingit (HAB Wolfenbüttel) ja Elea Rüstigit (Gottfried Wilhelm Leibniz Bibliothek Hannover) abi eest käsikirjade identifitseerimisel ja koopiate valmistamisel.

\section{Kirjandus ja käsikirjad}

Ahrens, Sabine 2004. Die Lehrkräfte der Universität Helmstedt (1576-1810). (Veröffentlichungen der Kreismuseen Helmstedt.) Helmstedt: Kreismuseum.

B r o ck m a n n, Reiner 2000. Teosed. Koost ja toim Endel Priidel. Tartu: Ilmamaa. Cale pinus, Ambrosius 1590. Dictionarium undecim linguarum: respondent autem latinis vocabulis hebraica, græca, gallica, italica, germanica, belgica, hispanica, polonica, ungarica, anglica. Basel: Henricpetri.

F aber Sor an us, Basilius 1696 [1571]. Thesaurus Eruditionis Scholasticae: Sive Supellex instructissima vocum, verborum, ac locutionum: tum rerum, sententiarum, adagiorum et exemplorum: quae docentibus juxta atque discentibus ad intelligendos solutae ac ligatae orationis Latinos Auctores, ...: Cum adjuncta in locis plerisque interpretatione Germanica; additis item dictionibus Graecis; syllabarum praeterea indicata quantitate / Jam Olim Post Aliorum Operas Per Augustum Buchnerum Recensitus, emendatus, et doctorum observationibus auctus. Novam Hanc Editionem post binas suas priores Christophorus Cellarius infinitis locis correxit, et innumeris accessionibus locupletavit. Accedit Index Germanicus vocum locutionumque copiosissimus. [Leipzig: Fritsch.]

Familie Meibom = Briefnachlass der Familie Meibom. - Gottfried Wilhelm Leibniz Bibliothek Hannover, MSXLII, 1874.

Glei, Reinhold 1997. Batrachomyomachia. - Der Neue Pauly, Bd. 2. Stuttgart: Metzler Verlag.

Holstein, Hugo 1893. Ernst Stapel. - Allgemeine Deutsche Biographie. Bd. 35. Leipzig: Duncker \& Humblot.

Kaj u, Katre, Vii d ing, Kristi 2014. Georg Locameruse reisialbum Andrea Alciato embleemiraamatus. Editsioon ja tõlge. - Tuna, nr 1, lk 61-73.

Klöker, Martin 2005. Literarisches Leben in Reval in der ersten Hälfte des 17. Jahrhunderts (1600-1657). Institutionen der Gelehrsamkeit und Dichten bei Gelegenheit. Bd. 1. (Frühe Neuzeit 112.) Tübingen: Niemeyer.

Klöker, Martin (ilmumas 2016). Die Geburt der estnischen Poetik aus der deutschen: Warum Reiner Brockmann kein „Buch von der Estnischen Poeterey” schrieb und trotzdem zum Begründer der estnischen Poetik wurde. - BaltischDeutsche Kulturbeziehungen im 16.-19. Jahrhundert: Medien, Institutionen, Akteure. Teil 1: Zwischen Reformation und Aufklärung. Heidelberg. [Ettekanne peetud samanimelisel konverentsil 2014. aastal].

L e p ajõ e, Marju 2009. Reiner Brockmanni värsside vältimatusest. - Keel ja Kirjandus, nr 10, lk 758-776.

L e p aj õ e, Marju 2013. Wotzu ist die tzung? Martin Lutheri keele- ja hariduskäsitusest. - Kroonikast kantaadini. Muusade kunstid kesk- ja varauusaegsel Eesti- 
ja Liivimaal. (Eesti Ajalooarhiivi Toimetised 20 (27).) Tartu: Eesti Ajalooarhiiv, lk 69-92.

L u th e r, Martin 1899. Werke. Kritische Gesamtausgabe. Bd. 15. Weimar: Böhlau. M e y er, Philipp 1957. Daetrius, Brandanus. - Neue Deutsche Biographie (NDB).

Bd. 3. Berlin: Duncker \& Humblot.

Sille m, Karl Hieronymus Wilhelm 1891. Die Matrikel des Akademischen Gymnasiums in Hamburg 1613-1883. Hamburg: Gräfe \& Sillem.

Stapelius [Stapel], Ernst 1630. Irenaromachia, Das ist Eine Newe TragicoComoedia von Fried und Krieg. Auctore Ernesto Stapelio Lemg. Westph. Acta Hamburgi Anno MDCXXX. Impressa typis Rebenlinianis. [Hamburg]

Tels ch ow 2000. Curriculum vitae. - Reiner Brockmann. Teosed. Koost ja toim

Endel Priidel. Tartu: Ilmamaa, lk 33-40.

\section{Young Brockmann on poetics}

Keywords: Reiner Brockmann, early modern poetics, occasional poetry, Brandanus Daetrius

One of the challenges in the reconstruction of the poetological program of Reiner Brockmann (1609-1648), the author of the first secular poems in Estonian, is the absence of personalia from his youth. Therefore it is difficult to decide which of his poetic principles had been acquired in Germany and which of them evolved in Estonia. Three Brockmann's autographs from September 1629 to October 1633 are retained in Gottfried Wilhelm Leibniz Library in Hannover, among the correspondence of the German scholarly family Meibom of the early modern era. In addition, Brockmann published 1630 a greeting poem on the occasion of the publication of the Irenaromachia by Ernst Stapel.

These newly founded sources indicate that in his early twenties Brockmann lived through an intense period of contemplation of theoretical as well as practical issues of poetry. In all his writings of the Hamburg-Rostock period Brockmann discusses the poetical practices of the time, including issues like versification, structure, choice of subjects and motifs, as well as the choice of a proper measure to express certain feelings. Nevertheless, the poetological interests of young Brockmann must have been merely theoretical as his own poems of that period were simple anagram poems consisting of elegiac distichs without any further experiments on form, language or meter. The possibility of vernaculars becoming a medium of poetry had not entered his mind yet, not even if the occasion to be celebrated was the publication of a vernacular book. At that time Brockmann makes no mention of Opitz or any other advocate of vernacular poetry. Consequently the winds of change did not touch Brockmann's poetic oeuvre until his settling down in Tallinn in 1634. The reason why it was Brockmann who went along with the multilingual and multiform poetic tradition practised in Tallinn, and not the rest of the literati of Tallinn Gymnasium, can probably be explained by Brockmann's active theoretical reflections on poetic issues in his pre-Tallinn period.

Kristi Viiding (b. 1972), PhD, Tartu University, Head of the Department of Classical Philology, Professor, kristi.viiding@ut.ee 